\title{
RUNYOGA
}

\section{FRÅN ARISK BLODSMYSTIK TILL NYANDLIG SJÄLVUTVECKLING}

\author{
Fredrik Gregorius \\ Linköpings universitet \\ fredrik.gregorius@liu.se
}

\begin{abstract}
Rune yoga is a spiritual practice based on the idea that the Runic alphabet can be used for spiritual and magical purposes. Based on an interpretation of the Runes where every letter in the alphabet is considered to contain within it a source of mystical powers Rune Yoga uses techniques inspired by Indian yoga to channel these forces. While contemporary Rune Yoga has become a part of Heathen and Alternative Spirituality that attracts people from a variety of Ethnic background the origin of the practice lies within the Ariosophical movement, a racial form of Esotericism that developed in Germany and Austria in the early 20th century. In this article the origin of Rune Yoga within the Ariosphical movement is presented, how it was integrated in ideas about Aryan racial supremacy. The article continues to show how Rune Yoga later migrated to North America and became a practice used within a non-racial milieu and what aspects remained from the original Ariosophical movement. The article argues that while some aspects of Ariosophical thinking remains within Rune Yoga the racial aspects have ceased to be important. Rather than focusing on race modern Rune Yoga focus in self-improvement for the individual and there is a lack of collectivist goals.
\end{abstract}

$$
\begin{gathered}
\text { KEYWORDS } \\
\text { ariosophy - yoga - magic - runes - heathenism - racism - rune magic }
\end{gathered}
$$

\section{INGRESS}

Runyoga är en nyandlig praktik baserad på föreställningar om att genom att ställa sin kropp i olika positioner som imiterar formen av de olika runorna går det att kanalisera runornas energier in i utövaren. Idag finns flera olika varianter av runyoga, och variationer kring vilket av de olika runalfabeten man avvänder sig av. Följande artikel har som syfte att presentera bakgrunden till den moderna runyogan som går att finna i förra 
sekelskiftets ariosofiska miljö i Tyskland och Österrike. Ariosofin var en utveckling av teosofin som menade att den ariska rasen var gudomlig och hade korrumperats genom rasblandning. Olika arisosofiska författare presenterade tekniker varigenom den ariska rasen kunde återta sin forna kraft och i den kontexten växer föreställningar om att det genom en form av gymnastik eller yoga var möjligt att agera som en antenn för olika kosmiska krafter. Genom runorna kunde dessa krafter kontrolleras. Artikeln har som syfte att visa på vilka delar av det ariosofiska arvet som lever kvar i dagens runyoga och hur det har ändrats genom att bli en del av moderna hedendom och ockultism i den engelskspråkiga världen efter andra världskriget.

\section{ATT NÄRMA SIG RUNORNA}

The first step in understanding rune lore is the understanding of the concept rune. A rune is not merely a letter in an old Germanic alphabet, but rather it bears the primary definition of "secret" or "mysterium". This basic meaning may be easily compared to the use of arcana in connection with the Tarot. Therefore, a rune is primarily a secret, holy concept or idea that must be expressed or dealt with in concealment. Throughout this work "rune" should be understood first in the sense of a secret and holy concept (Thorson 1984: 1).

Vad är runorna? Var de, som de flesta runologer idag menar, primärt ett alfabet som utvecklades under 100-talet bland de germanska stammarna och senare spred sig över Skandinavien, baserat på det latinska? Eller hade runorna en mer esoterisk och magisk funktion? Referenser till att runor skulle använts i magiska sammanhang finns på ett flertal ställen, från Tacitus Germania (skriven runt 98 evt) som beskriver hur germanerna använder sig av en form av spådom med tecken ristade på träbitar, till Edda-texterna och de forn-isländska sagornas referenser till runorna som fyllda med kraft och magi (Tacitus 1980: 145-147, O’Donoghue 2007). Begreppet, runa har etymologiskt också sin betydelse av "hemlighet och mysterie". I Hávamál kan vi läsa hur Oden genomgår en plågsam ritual eller initiation för att få kunskap om runorna:

Nam ek upp rúnar, .pandi nam, fell ek aptr flàan.

Jag tog upp runor, Med rop jag tog dem, Så föll jag därifrån (Hávamál vers 139, citerat ur Eddan 1992: 36)

I kontrast verkar de bevarade runinskriptioner oftast vara av en mer vardaglig karaktär, utan ett magiskt syfte. Vi vet inte heller vad som menades med runor i den medeltida 
isländska litteraturen, eller vad för tecken som Tacitus refererar till. Var bokstäverna heliga och magiska eller var det en fråga om besvärjelser? Om frågan inom den akademiska runologin idag lutar mot att runorna oftast användes som ett vanligt alfabet har föreställningar om runorna som långt äldre än 100-talet och med ett djupare magiskt syfte existerat sedan 1500-talet (O’Donoghue 2007). Från göticismen i Sverige till dagens nyandliga miljö finner vi föreställningar om att runorna är något mer än ett alfabet. De är en portal till magiska krafter och kunskaper bortom det rationella. Ovanstående citat från Edred Thorsons Futhark: A Handbook of Rune Magic exemplifierar en sådan syn. Runorna ses som kärl för esoterisk och magisk kunskap och varje runa i sig har multipla lager av meningar och magiska funktioner. Även om rötterna till ett sådant synsätt framträder redan på 1500-talet är det i början av 1900-talet som spekulationer om runornas magiska egenskaper formas till en strukturerad magisk praktik. Idag har runor blivit en återkommande del av nyandlighet och nyhedendom, speciellt som ett redskap för spådom där runorna tillsammans med tarotkort blivit en av de mest populära divinationsmetoderna. Det finns ett flertal introduktionsböcker med titlar som Runes for Beginners av Lisa Chamberlain, Modern Runes av Vervain Helsdottir, The Beginners Guide to Runes av Josh Simonds och Futhark av Edred Thorson.

Runkort, runstenar och smycken med runor kan köpas i de flesta nyandliga butiker och säljs oftast med förklaringar om vad de olika runorna har för egenskaper, vilka som kan ge framgång, kärlek eller styrka. En hel del av runkorten påminner starkt om tarokkort med bilder, ofta med gudar och gudinnor, som illustrerar betydelsen av varje runa, som Rune Oracle Cards från 2013 eller Power of the Runes Deck, publicerad redan 1998. Andra kort består endast av bilder på runorna själva. Runorna säljs med löften om att låta dig både se framtiden och förändra den. I den synkretistiska moderna nyandligheten är det inte överraskande att runorna också presenteras som att de kan användas inom andra andliga och magiska system. Det finns idag bland annat run-baserad astrologi, meditationer, och yoga. Det sistnämnda är vad föreliggande artikel kommer fokusera på.

I likhet med andra nyandliga tolkningar av runorna är runyoga baserad på föreställningen om att de fornnordiska runorna inte enbart var ett alfabet utan hade en djupare och mer esoterisk innebörd. I fallet med runyoga är grundteorin att runorna illustrerar olika positioner likande de olika asanas som man hittar i den moderna populariserade indiska yogan. Runyoga återfinns speciellt inom de mer esoteriska formerna av nyhedendom. Idag går det att hitta instruktioner om hur man ska utföra runyoga på Youtube, kurser arrangeras och i olika böcker om runmagi har runyoga blivit en återkommande praktik. Bland de som utövar runyoga varierar förklaringarna kring varifrån det kommer. En del menar att det handlar om en tusenårig tradition, medan andra är medvetna om att det är en modern konstruktion från 30-talet. Vad som är intressant är att modern runyoga idag framstår som en relativt neutral företeelse med fokus på självutveckling, samtidigt som det ursprung på 30-talet som refererades till var djupt baserat på, och växte fram ur 
en miljö där ras och ursprung var centrala komponenter. Följande artikel kommer följa utvecklingen av runyogans uppkomst i en miljö som drömde om ariska gudamänniskor fram till dagens nyandliga utövare.

\section{OCKULTISM I WeIMAR}

Den moderna runmagin, liksom runyoga eller rungymnastik, växer fram inom den ockulta miljön i Tyskland och Österrike under det tidiga 1900-talet. Speciellt sker det inom en utveckling av teosofin kallad ariosofi. Ariosofins grundföreställning var att den ariska rasen var gudomlig, men hade korrumperats genom rasblandning (Goodrick-Clarke 1992: 2). Begreppet myntades 1915 av Jörg Lanz von Liebenfels (1874-1954). Tidigare hade Liebenfels använt termen "ario-kristendom" eller "theozoologi" (Goodrick-Clarke 1992: 227). Ariosofin kan ses som en rasbaserad tolkning av teosofin, speciellt var man intresserad av Blavatskys teorier om rotraser. I kontrast till teosofins teoretiska mål av ett universellt brödraskap var ariosoferna endast intresserade av den ariska rasen som man såg som den enda kulturskapande mänskliga rasen och de rena arierna tillskrevs en gudomlig status med övernaturliga förmågor. Då dessa föreställningar inte uppkom förrän 1915 har Nicolas Goodrick-Clarke föreslagit att begreppet används som ett familjebegrepp även för ideologiskt närliggande rörelser och författare innan 1915 (1992: 1). Begreppet ariosofi används därmed här som en kategorisering av en ideologisk strömning inom den tyska ockulta miljön som existerade innan 1915.

På grund av de senare oftast överdrivna associationerna mellan ockulta intressen och nationalsocialismen har ariosofin fått en särställning i studiet av ockultism under Weimar-republiken och fått rollen som den definierande formen av ockultism för eran. I Corina Treitels $A$ Science for the Soul: Occultism and the Genesis of the German Modern, presenteras en mer komplex bild där flera av det tidiga 1900-talets esoteriska tänkare i Tyskland snarare hade en pro-modernistisk hållning med liberala och även socialistiska värderingar. Treitel menar att även om man inte ska bortse från en koppling mellan "völkisch"-baserad ockultism och bland annat teosofi så var ariosofin inte så dominerande som den tidigare presenterats. Under 20-talet i Tyskland fanns det endast åtta grupper som praktiserade ariosofi medan över 50 som praktiserade konventionell teosofi (Treitel 2004: 103). Ariosofin var likväl en del av samma sociala och kulturella miljö som de mer liberala formerna av ockultism.

Sekelskiftesockultism präglades av en vetenskaplig terminologi, delvis baserad på teosofernas försök att presentera esoterism som en form av vetenskap, och delvis på spiritualismen. Seanser presenterades som laboratorier varigenom man kunde nå kunskap om dolda dimensioner i tillvaron (Treitel 2004: 7-17). Utvecklingen av radio och elektricitet fascinerade och inom ockulta kretsar förekom föreställningar baserade på att om det var möjligt att höra röster genom radiovågor, som inte var synliga eller gick att känna, då borde det även finnas liknande andliga vågor som man kunde påverkas av och påverka. En annan aspekt var en kult kring vitalism och vitalitet, vilket var en del av 
en bredare idéströmning i Tyskland vid förra sekelskiftet (Hau 2003). Detta är tydligt i den ariosofiska rörelsen som binder samman hälsa med rasrenhet men det var även föreställningar som fanns hos icke-rasistiska esoteriker.

\section{VÖLKISCH-RÖRELSEN}

Ariosofin var inte enbart en del av den ockulta miljön, man var också en produkt av den så kallade völkisch-rörelsen. Även om völkisch-rörelsen förenades i tankar om att återuppväcka den germanska kulturen var den löst sammansatt och det fanns stora ideologiska skillnader. Baserad på föreställningar om kopplingen mellan folk, nation och jord såg den människan som rotad i den plats hon hade sitt ursprung. George L. Mosse ser völkisch-rörelsen som en direkt produkt av den tyska romantiken och ställer den i kontrast till rationalism och upplysning. Mosse skriver:

The fine distinctions and restrictions of the intellectual systems and rational ideologies of the eighteenth century had been inundated by what many men took to be inevitable social and historic forces. The patient experimentaion and intellectual discipline of the Enlightenment were succeded by the ideal of revolution, and the concept of an intelligible God gave way to a pantheistic view of the universe (Mosse 1981: 13).

För Mosse var völkisch-rörelsen en kapitulation till irrationalism där romantiska känslostormar blev vägen till kunskap. I den miljön blir folket ett i det närmaste metafysiskt begrepp där varje folk har sin volksgeist och det är endast genom en förening med denna som tillvaron blir autentisk. Eftersom folket sågs som evigt fanns en strävan efter ursprung och att hitta essensen av folket i historien. I Tyskland söktes det urgermanska i folksagor, arkeologi och antika texter som Germania av Tacitus (Mosse 1981: 67-87). I en ideologisk miljö där jord, folk och ursprung fick en så stor betydelse fick de som inte passade in rollen som "den andre". Framför allt blev det fallet med judarna som sågs som rotlösa och utan en plats i en kultur baserad på "blod och jord". Bilden av juden skiftade från tragisk till demonisk (Mosse 1981: 126). Inom ariosofin skulle det bli en tonvikt på det demoniska.

Den skarpa distinktion mellan rationalism och irrationalism som Mosse presenterar har kritiserats som för binär och simplistisk, liksom hans bild av völkisch-rörelsen som den direkta ideologiska föregångaren för nationalsocialismen. Treitel och GoodrickClarke har båda lyft fram att kopplingen mellan völkisch-rörelsen, ockultism och nationalsocialism var mer ambivalent (Treitel 2004: 25-27; Goodrick-Clarke 1992). För Mosse var ockultismen bara ännu ett uttryck för irrationalismen som präglade den djupa kris i Tysklands intellektuella liv han såg, något som enligt Treitel dock saknar empiriskt stöd (2004: 26). 
Mosses fokusering på det irrationella blir också ett hinder för att förstå utvecklingen av ariosofin och runmagin. Det fanns onekligen en föreställning om att det germanska psyket var mer lagd åt det dunkla och emotionella, speciellt inom romantiken, och att det förekom visionära upplevelser där mystiker hävdade att de erhållit kunskap från övernaturliga källor. Men samtidigt användes ofta ett vetenskapligt språkbruk, även om det användes i en oortodox form. Trots den romantiska sturm und drang-vurmen användes "vetenskap" som ett sätt att skapa legitimitet i linje med det som tidigare varit fallet med teosofin och som fortfarande är fallet med mycket av dagens nyandlighet och New Age. Den här formen av retorik har analyserats av Olav Hammer i Claiming Knowledge (2003) och samma form av retoriska grepp kring "vetenskapligt" språk är även närvarande inom ariosofin.

\section{RUNORNAS HEMLIGHETER}

Den moderna runmagins fader var den österrikiske författaren och journalisten Guido List (1848-1919). List lade senare till "von" så hans namn skulle låta mer aristokratiskt, en vanlig trend bland förra sekelskiftets ockultister i Europa vilka oftast hade en mer borgerlig bakgrund än de var bekväma med och ville ge en mer nobel bakgrund till sig själva. För List gick fixeringen vid adelstitlar längre och i sin romantisering av medeltidens feodalsamhälle tolkade han in esoteriska koder i olika släktvapen och såg adelssläkter som bärare av esoterisk kunskap. Enligt List dolde sig där spår av den forngermanska kulten kring Wotan (List 1910). Eftersom Lists tankar var baserade på blodets renhet fanns även tankar om att adelsfamiljer hade bevarat blodet, och därmed var kontakten med det urgermanska intakt.

List växte upp i Wien i en välmående katolsk medelklassfamilj. I unga år blev han fascinerad av den forngermanska religionen och vid 14 års ålder avsvor hans sig kristendomen och dedikerat sig till Wotan. Han svor en ed att när han blivit stor skulle han bygga ett tempel åt Wotan: "Wenn ich einmal groß bin, werde ich einen Woutanstempel bauen!" (List 1913: 592). Allt detta bygger på Lists egna beskrivningar, och bör ses som ett sätt för honom att lyfta fram hans starka dedikation till Wotan.

Det mest betydande verket för utvecklingen av modern runmagi var Das Geheimnis der Runen (Runornas hemlighet), 1908. Boken byggde på visioner List hade haft när han 1902 genomgick en ögonoperation som lämnade honom temporärt blind. Under den perioden fick List visioner av de olika runorna, deras betydelse och efter det såg han det som sin mission att sprida sina nya insikter och därigenom vitalisera det germanska folket genom att återvända till sitt ursprung. Även om List först 1908 publicerade sitt runmagiska system hade han redan tidigare skrivit om liknande ämnen. Under flera år arbetade List som journalist och skrev för oftast konservativa tidskrifter. Hans texter präglades av hans fascination för germansk forntid och hur spår av Wotan-kulten kunde ses i folktro, landskap och heraldik (Lenthe 2018: 28-37; List 1913). 
Det runmagiska system List skapade byggde på en tolkning av Ljóðatal, en del av Hávamál som består av arton verser eller sånger och består av verserna 147-164. Enligt List representerade varje sång en specifik runa. Snarare än att bygga på existerande runalfabet skapade List sitt eget, som han dock menade var uråldrigt (List 1912). List kallade dessa för Armanen-runor från hans teori om Armanenschaft. Armanenschaft var enligt List namnet på det hemliga sällskap av hedniska präster som bar germanernas esoteriska visdom. Wotanismen var religionens exoteriska dimension och armanismen den esoteriska. I opposition till Armanenordern stod kristendomen, och framför allt judendomen. Judendomen strävade efter att förinta den ariska rasen genom att lösa upp nationerna. Speciellt såg List idag detta inom den växande socialismen och industrialismen (Goodrick-Clarke 1992: 79-81).

Lists världsbild byggde tydligt på völkisch-rörelsens syn på människan som en produkt av sitt folk och där äldre, nedärvd kunskap var det sätt varigenom samhället kunde räddas. Genom folket kunde den germanska människan sträva efter att leva i förening med det gudomliga, och agera i harmoni med den gudomliga viljan. Bilden av Gud var panteistisk och det gudomliga finns i världen omkring oss, i naturen, språk och framför allt i folket snarare än separerat från skapelsen (List 1912; Flowers och List 1988: 20f). Föreställningen om att det gudomliga finns inom oss, och i världen blir central för utvecklingen av runmagi, där senare runyoga uppkommer som en underkatogori.

List trodde på en form av reinkarnation där själen återföddes till samma folk och därigenom existerade inom folket ett kollektivt minne vari nyckeln till det förflutna låg dolt. Lists syn på världen är både holistisk och dualistisk. För List är ordning det goda och kaos det onda och destruktiva. Det goda och högsta associeras med maskulinitet och kaos och förvirring associeras med det feminina. Denna dualism återkommer genomgående hos List, som ser det moderna samhället, speciellt urbanisering, demokrati, feminism som tecken på förfall och är ett återkommande drag i andra former av ariosofi som ser förändrade relationer mellan män och kvinnor som ett tecken på kulturell kollaps (List 1912: 19; Goodrick-Clarke 1992: 81).

List presenterade inga praktiska övningar i sina texter utan de hade som syfte att ge en teoretisk ram varigenom läsaren kunde återupptäcka runornas mysterier själv. Dock fanns det försök till att organisera Lists anhängare. 1908 grundade List och hans anhängare Guido-von-List-Gesellschaft, och 1911 Hoher Armanen-Orden (HAO) en inre cirkel för hans närmaste lärjungar. List dog 1919, 71 år gammal, efter att ha förutspått en ny guldålder när Tyskland skulle segra i första världskriget (Goodrick-Clarke 1992: 85).

Lists inflytande har varit centralt för all form av modern runmagi. I Tyskland är det först under senare delen av 1900-talet som runmagiska texter och sällskap har tagit upp andra former av runor som den äldre Futharken. Trots Lists tydligt rasbaserade form av runmagi har flera författare försökt skapa versioner av hans system som inte har haft rasistiska undertoner (Thorson 2018: 36-41; von Schnurbein 2016: 117). Om det har varit 
möjligt eller ej med List kan diskuteras, men med den andra centrala gestalten i utvecklingen av ariosofin, Jörg Lans von Liebenfels har en sådan utveckling varit omöjlig.

\section{JÖRG LANS VON LIEBENFELS}

Jörg Lans Liebenfels är en av de mest omdebatterade och egendomliga ockulta författarna från det tidiga 1900-talet. Hans blandning av List, teosofi, rasbiologi och bibelexeges skapade en av de mest extrema formerna av rasbaserad ockultism. Dock var det ur kretsen kring Liebenfels som runyoga, genom Sigfried Adolf Kummer (1899-?), skulle etableras. Liebenfels var tidigt aktiv i den ariosofiska rörelsen, han var en av de 50 första medlemmarna som 1908 gick med i Guido-von-List-Gesellschaft och, som nämnts ovan, den som myntade begreppet 1915. I likhet med List lade Liebenfels senare till ett "von" i sitt namn. Liebenfels hade tidigare varit munk i Cisterciensorden. 1894 hävdade han att han hade blivit upplyst och började predika en världsbild av evig kamp där de högre och ädlare raserna stod i opposition till de lägre. 1899 blev han inte helt överraskande utesluten ur Cisterciensordern. 1905 gavs hans mest centrala verk ut, Theozoologie oder die Kunde von den Sodoms-Äfflingen und dem Götter-Elektron. I grunden är boken en tolkning av Bibeln där Eva är den ursprungliga ariska och gudomliga kvinnan och Adam en apmänniska, eller demon. Adam försöker genom både våldtäkt och genom att förföra Eva fördärva hennes renhet och därmed även ta bort hennes psykiska förmågor då den ariska rasen var gudomlig. Arierna reproducerade sig inte genom fysiskt sex utan genom elektricitet. Genom att ha sex med Adam har Eva dragit ner den ariska rasen och fördärvat både sig själv och sin avkomma. Enligt Liebenfels är detta skäl till att kvinnor är svagare och mer sexuellt attraherade till mörka män. Under århundraden har gradvis den ariska rasen blivit alltmer försvagad. Den sista rena ariern, och därmed en person med övernaturliga förmågor, var Jesus. Enligt Liebenfels var berättelsen om korsfästelsen egentligen en gruppvåldtäkt för att ta bort Jesus övernaturliga förmågor. Dock kunde den ariska rasen återta sina ursprungliga gudomliga förmågor genom att göra sig av med de lägre raserna genom sterilisering, kontrollera ariska kvinnor vars vilja var svagare och komprometterad, och endast låta de renaste reproducera (Liebenfels 2002; (Goodrick-Clarke 1992: 91-94)). Liebenfels var inspirerad av Blavatskys teorier om olika rotraser och speciellt de sektioner i The Secret Doctrine som beskriver hur de högre andliga raserna faller ner i materia något som Liebenfels tolkade som att rasblandning som en orsak till tidigare civilisationers förfall. Centralt för Liebenfels var Blavatskys kommentarer i The Secret Doctrine till det åttonde kapitlet av Book of Dzyan, en text Blavatsky hävdade var en uråldrig Tibetansk text. Speciellt vers 32 var betydande:

And those which had Spark (the "narrow" brained) took huge she-animals unto them. They begat upon them dumb races. Dumb they were themselves. But their tongue untied. The tongues of their progeny remained still. 
Monsters they bred. A race of crooked red-hair covered monsters going on all fours. A dumb race to keep the shame untold (Blavatsky 1888: 184).

En annan betydande inspirationskälla för Liebenfels var Otto Weiningers (1880-1903) Geschlecht und Charakter (Kön och karaktär) från 1903. Trots att Weininger hade en judisk bakgrund gav han i sina böcker uttryck för grova antisemitiska föreställningar. Weiningers bild av judendomen baserade sig på en uppfattning om att skillnaden mellan maskulint och feminint genomsyrade allt, inklusive kulturer och folk. Det maskulina var aktivt, rationellt, moraliskt och medvetet medan det kvinnliga var passivt, irrationellt, omoraliskt och omedvetet (Weininger 2015). Manliga och kvinnliga sidor finns inom alla människor men är mer eller mindre framträdande, och även kulturer och hela folk var formade av starkare maskulina eller feminina sidor. Judendomen var feminin och därmed amoralisk och irrationell. Målet med Weiningers tankar var att frigöra sig från det feminina som drog ner det manligt rationella subjektet och sträva mot det högre. Tillvarons syfte var att föda fram geniet och det var endast män som hade i sig möjligheten till genius. Weininger tog livet av sig samma år som hans bok publicerades 1903, endast 23 år gammal. Weiningers tankar märks tydligt hos Liebenfels i fixeringen hur det feminina korrumperar ner det manliga subjektet, samt i antisemitismen och dualismen. Trots den pessimistiska syn på världen som Liebenfels hade var han också fascinerad av moderna upptäckter som radiologi och elektronik och integrerade detta i sin världsbild. Detta ger Theozoologie en ytterligare dimension av excentricitet men är betydande genom att även Liebenfels använde sig av sin samtids vetenskapliga terminologi för att legitimera sina teorier (Goodrick-Clarke 1992: 95). Trots den extrema och bisarra världsbild som Liebenfels presenterade lyckades han få anhängare och etablerade ett sällskap för sina idéer Ordo Novi Templi (Det nya templets order), som dock inte lyckades få mer än ett hundratal medlemmar (Gardell 2003: 23).

Den arisofiska rörelse byggde på ett dualistiskt universum där ordning står mot kaos, gott mot ont, det högre mot det lägre, det manliga mot det kvinnliga, det ariska mot det judiska, tradition mot modernitet. Men man byggde också på föreställningar om dolda energier och magiska tankar om elektricitet. Tankar om detta skulle bli fundamentet för utvecklingen av runyoga och rungymnastik.

\section{RUNGYMNASTIK OCH RUNYOGA}

Varken List eller Liebenfels utvecklade en konkret praktik men hade lagt den teoretiska grunden för en sådan. Genom Lists föreställningar skapades grunden för en föreställning om runorna som bärare av uråldrig och magisk kraft och genom Liebenfels fördes föreställningar in om hur den ariska människans besatt en inre gudomliga kraft som kunde frigöras. Vägen till denna frigörelse blev att skapa ett praktiskt system av runorna. Den första som försökte göra om runorna till en form av yoga var Friedrich Bernhard 
Marby (1882-1966). 1931 gav han ut Runenschrift, Runenwort, Runengymnastik. Marby formade i hög grad den praktik som senare skulle bli känd som runyoga av Kummer. Grunden var att kanalisera runkraften runt, i och omkring sig själv (Thorson 2018: 1921). I kontrast till sina föregångare skapade Marby ett praktiskt system varigenom de krafter och energier som List och Liebenfels refererat till kunde kanaliseras.

Marbys system, som det presenteras i Thorsons systematisering av hans verk, bygger på fem kosmiska zoner som runmagikern kunde kanalisera och använda sig av, dessa var 1) den inre-jordens rymd, 2) den materiella jordens rymd, 3) vågornas rymd, 4) kosmisk rymd och 5) super-kosmisk rymd (Thorson 2018: 59). Runmagikern arbetar med alla dessa dimensioner och kan kanalisera in dess krafter genom runorna. Speciellt skulle rungymnastik utföras vid olika kraftplatser som ruiner, berg och vid vatten (GoodrickClarke 1992: 161). Den första formen, den som kallas inre-jorden rymd bygger på Marbys tro på att jorden var ihålig och att det kunde finnas ett universum under oss, en teori som existerade som en underströmning bland en del esoteriska författare från 1700-talet fram till idag (Godwin 1996). Politiskt sett stödde Marby nationalsocialismen men blev 1936 censurerad och spenderade resten av kriget i olika läger (Thorson 2018: 21). Trots att han kom i opposition med nationalsocialismen så formade föreställningar om arisk överlägsenhet och antisemitism Marbys tänkande. Det finns dock olika bedömningar om hur djupt rotade dessa föreställningar var. Goodrick-Clarke menar att Marbys system var producerat i en "less explicitly Aryan racist context", dock utvecklar han inte sina resonemang kring detta och Alan Baker i Invisible Eagle: The History of Nazi Occultism menar att Marby inte byggde direkt på antisemitism utan snarare på att runorna hade positiva hälsoeffekter (Thorson 2018: 20f; Goodrick-Clarke 1992: 160; Baker 2000: 59). Varken Goodrick-Clarke eller Baker ger några tydliga argument för sin position och att framhålla hälsa står knappast i opposition till att vilja bygga upp den ariska rasen. Stefanie von Schnurbein lyfter fram en annan sida av Marby där det ariosofiska draget är tydligt:

Marby, and later his post-war publisher, Rudolf Arnold Spieth, were both adamant that its "Rassische Gymnastic" (racial gymnastics) was to be understood as an "Aufrassungsweg" (path of racial improvment), wich was to be strictly reserved for members of the "Germanic Race" (2016: 116).

Bredvid Marby var den centrala personen i utvecklingen av runyoga Siegfried Adolf Kummer. Kummer bygger vidare på Marby under namnet Runenyoga. Kummer var liksom Marby inspirerad av List och bygger sitt runmagiska system på List (Kummer 2017: 7-10). Relativt lite är känt om Kummer. Han föddes 1899 och hade 1927 etablerat en "run-skola" i Dresden under namnet Runa. Kummer lade en stor tonvikt vid den praktiska sidan av run-magi. Målet var att vitalisera det tyska folket genom andliga övningar som kunde dra energi från jorden. Kummer samarbetade med ariosofiska rörelser och det är tydligt att hans teorier byggde på föreställningar om att den ariska rasen hade en 
speciell kraft som behövde frigöras. I likhet med samtida esoteriska tänkare som Liebenfels var Kummer fascinerad av elektricitet och radiovågor som var osynliga för blotta ögat men kunde påverka den materiella världen. På samma sätt kunde germanerna genom runövningar och dans reglera och kontrollera de kosmiska vågorna omkring henne. Ett hot mot detta var att låta sin ariska renhet bli besmittad och Kummer varnar för "Rassenschuld", rasskuld, hans begrepp för rasblanding, eller för att låta lägre begär leda ens arbete med runorna (Kummer 2017: 35, 43).

Kummer var mer inspirerad av rituell magi än Marby och lärde ut hur runmagikern skulle göra skyddande cirklar runt sig med namnet från germanska gudar och hade en mer ceremoniel magisk syn på andlig praktik än många andra samtida runmagiker (Kummer 2017: 11, Goodrick-Clarke 1992: 161f). 1932 ger han ut sin första bok Heilige Runenmacht som 1933 följs upp av Runen-Magie. Speciellt den senare kommer bli betydande då den presenterar olika former av kroppspositioner varigenom runmagikern kan kanalisera in runornas kraft och även olika handrörelser, en form av mudras som kan användas av samma skäl (Kummer 2017: 15).

Vad som senare händer med Kummer är oklart. Han hamnar i likhet som Marby i onåd hos den nationalsocialistiska regimen, och hans och Marbys namn är med på den lista av ockultister som enligt Karl Maria Willigut, Heinrich Himmlers "andlige" rådgivare, hade korrumperat den germanska kulturen (Goodrick-Clarke 1992: 162).

Att både Marby och Kummer hamnade i onåd hos den nya regimen, trots att de delade liknande värderingar kring ras och antisemitism är inte speciellt överraskande. Även Jörgen Lanz von Libenfelts organisation ONT hamnade i konflikt med den nya nationalsocialistiska regimen. Det fanns olika orsaker. Delvis handlade det om att flera av sällskapen var organiserade som hemliga sällskap vilket inte var tillåtet. Det går dock inte att undvika att se att ett av skälen var hur en del konkurrerande ariosofiska tänkare som Karl Maria Willigut som hade starka kopplingar till SS-divisionen Ahnenerbe, såg möjligheten från sin position att göra sig av med konkurrenter. Det bör också noteras att bilden av nationalsocialismen som fylld av ockulta teorier saknar egentligt stöd. (Pringle 2006; Treitel 2004: 212-216).

Marbys och Kummers problem med nationalsocialisterna betydde inte att deras tankar skulle varit mildare eller mer toleranta $\mathrm{i}$ frågan om ras. De byggde båda vidare på List och Liebenfels och såg i sina övningar en väg varigenom den ariska människan kunde hitta sin inre kraft och befria sig från det lägre, det som kallades för "äfflingar". Rasistiska föreställningar genomsyrar därmed både Marby och Kummers verk liksom föreställningar om att runorna är en väg till en uråldrig visdomstradition som kan generera och vitalisera den germanska kulturen (von Schnurbein 2016: 115). Alla var del av en miljö som såg det moderna samhället som förfallet. Speciellt såg man demokrati, mångkultur och modernitet som tecken på detta. Det fanns olika historier om hur förfallet hade börjat, hur långt det hade gått och vad som kunde göras för att stoppa det men en nödvändig lösning för alla var att stoppa rasblandning. 
Men all inspiration behövde inte komma från det nuvarande Tyskland. En grundläggande ideologisk komponent var att den ariska rasen var den högsta av alla former av mänsklighet och besatt gudomliga förmågor som kunde återuppväckas. På grund av bilden av arier som den högsta rasen fanns även föreställningar om att alla kulturer hade skapats av arier vilket inkluderade Grekland, Rom och Indien. Indien ansågs vara skapat av arier och kastsystemet tolkades som ett sätt att försöka förhindra rasblandning. Med den framväxande komparativa språkvetenskapen så ökade intresset för Indien genom upptäckten av att det fanns en språklig gemenskap mellan sanskrit och europeiska språk, men inte hebreiska. Inom den akademiska forskningen kring indoeuropeiska språk fanns onekligen nationalistiska föreställningar men inom den ariosofiska fick den en långt mer spekulativ form (O’Donoghue 2007). En central tanke var existensen av ett urhem, den plats varifrån den ariska rasen kom. Ariosoferna placerade sällan urhemmet i Indien utan i stället ansåg man att arierna måste komma från norr. En inte ovanlig tanke var bland annat Nordpolen, i vad som sågs som Hyperborea. Arierna var en invaderande ras från norr som etablerat det vediska systemet i Indien menade man. Att använda sig av tekniker som yoga var därmed inget konstigt, det var inte egentligen indierna som skapat yoga, utan germanerna och båda var en del av samma ur-ariska kultur med rötter i det fjärran norr (O’Donoghue 2007).

\section{StADHAGALDR: RunYOga I AMERIKA}

Efter 1945 blev runorna associerade med nazismen och det fanns en ökad misstänksamhet gentemot dem. Trots detta fortsatte det att existera en levande runmagisk tradition efter andra världskriget och Armanen-runorna fortsatte vara normen (von Schnurbein 2016: 117). Flera författare försökte presentera en version av armanen-runorna som inte baserade sig på rasmystik och antisemitism. Den mest kända av dessa var Karl Spiesberger som 1955 publicerade Runemagie. Spiesberger bygger på List men har tagit bort den rasistiska överbyggnaden. Utveckling efter 1945 gör att magiska tekniker associerade med ariosofin kunde ges nya former och få en ny publik och under slutet av 70-talet börjar även runyoga och tysk runmagi sprida sig till den engelskspråkiga världen. Enligt von Schnurbein fanns det hos Spiesberger förvisso en kritik mot nazisterna men inget om att även för List, Marby och Kummer var rasismen ett grundläggande element (von Schnurbein 2016: 117).

I den engelskspråkiga världen kommer runyoga att populariseras och integreras som en del av rumagisk praktik genom Edred Thorson (Stephen Flowers). I Futhark: A Handbook of Rune Magic introducerar Thorson runyoga som en central del av hans rumagiska tekniker. Boken gavs första gången ut 1984 och har blivit en av de mest betydande böckerna i den engelskspråkiga världen om runmagi.

Thorson eller Stephen Flowers är en betydande men kontroversiell författare inom den amerikanska hedniska miljön och har kritiserats för att popularisera nazi-ockultism och hysa sympatier för satanistiska organisationer. Orsaken till den senare anklagelsen 
är att Flowers sedan 1984 varit medlem i Temple of Set, en utbrytargrupp ur Church of Satan. Organisationen kan inte själva anses vara satanistisk utan snarare en form av post-satanism (Granholm 2013). Något som har varit mer omdebatterat har varit Flowers ambivalenta relation till rasbaserade former av asatro och hedendom. Flowers har översatt ett flertal verk av ariosofiska författare till engelska och har varit central i att popularisera deras tankar i den engelskspråkiga världen. Bland annat har han översatt List, Peryt Shou, Kummer och även skrivit om dem i ett antal av sina verk. Flowers har oftast tonat ner de rasistiska och antisemitiska aspekterna av ariosoferna och har själv undvikit att ge uttryck för rasideologiska eller antisemitiska åsikter. Dock har han kritiserats för att inte ta starkare ställning mot rasbaserade tolkningar av hedendom och har på senare år även gett uttryck för sympatier för europeiska nya-högerförfattare som Alain de Benoist. Generellt menar dock Flowers att hans verk är opolitiska (Gardell 2003: 162, 164; Flowers 2002; von Schnurbein 2016: 287).

1979/80 runt årskiftet grundade Flowers Rune Gild, en magisk order för att utforska runornas magiska och esoteriska dimensioner. Rune Gild inkorporerade runyoga i sin praktik vilket tydligt kan ses i Nine Doors to Midgaard, den bok som används som grundbok för nya medlemmar i sällskapet. 1984 disputerade Flowers vid University of Texas i Austin, med avhandlingen Runes and Magic: Magical Formulaic Elements in the Elder Tradition. I den driver Flowers tesen att runorna användes för magiska syften. Även om Flowers haft som ambition att ge ut akademiska verk under sitt riktiga namn och magiska under namnet Edred Thorson har även hans senare arbeten under namnet Stephen Flowers formats av hans magiska övertygelser. Samma år som han disputerade gav han även ut Futhark: A Handbook of Rune Magic som blivit en av hans mest lästa böcker och fungerar som en introduktion till runmagi. I boken presenteras även en form av runyoga som en del av praktiken.

I Futhark använder Thorson begreppet "stadhagaldr" för runyoga. Begreppet tycks vara en kombination av stadh, vilket skulle kunna översättas med att stå eller vara positionerad, och Galdr som hos Thorson refererar till magiska besvärjelser. ${ }^{1}$ Thorson hänvisar till Kummer och Marby men menar att de varit för påverkade och beroende av indiska förlagor. Thorson skriver:

In comparison to what yoga became in later centuries, stadhagaldr is an active system of magic that consists of the assumption of runic postures or gestures for magical effect, both within the vitki and in his or her enviroment. Both systems are most probably derived from the same common Indo-European root tradition of magical and symbolic gestures (1984: 124).

1. Är här tacksam för den hjälp jag fått av Benjamin Weber Pedersen för att reda ut etymologin av begreppet. 
Thorson återvänder i ett flertal av sina verk till samma grundtanke, att stadhagaldr är en form av ur-indo-europeisk tradition där yoga bara är en annan version av samma grundteknik. Som argument för detta refererar han till bilderna på Gallehushornen som han menar illustrerar bilder på människor som utför något som kan liknas vid yoga eller stadhagaldr (1994: 17). Dock menar han att det endast finns fragment av detta kvar så i grunden måste den moderna utövaren bygga på Marby och Kummer. I kontrast till Kummer och Marby bygger Thorson inte på Lists Armanen-runor, som han anser vara otraditionella, utan på den äldre Futharken. Det saknas också tankar om att vitalisera något kollektiv som den ariska rasen och i stället läggs fokus på utveckling av den egna individen:

Stadhagaldr is used as a mode of psychological integration and personal transmutation, and it is also employed in all other types of magical operations. The vitiki may, for example, litterally build a numious, living runic talisman within the body through stadhagaldr, so that he or she becomes a walking rune tine! (1984: 125).

Thorson skriver också att stadhagaldr har sex primära mål: "Control of the body, control of thoughts, control of Breath, control of Emotions, anchoring of the Rune, mastering of the Will" (Thorson 1984: 125)

De sex målen Thorson ställer upp påminner om de beskrivningarna av hathayoga som det presenterades hos västerländska författare under första hälften av 1900-talet. Ett tydligt på detta är Aleister Crowleys Eight Lectures on Yoga från 1939, som även associerar utvecklingen av vilja med yoga (Crowley 1972: 16). Hos Thorson blir fokus på att utveckla sig själv, lära sig självkontroll och de mer kollektiva mål som fanns i den ariosofiska miljön är borta. Det vi därmed ser är en förändring av synen på både runyoga och runmagi generellt, och den blir en del av den framväxande efterkrigstidens subjektivt inriktade nyandlighet.

\section{HUR FUNGERAR RUNYOGA}

Den grundläggande praktiken inom runyoga har inte ändrats signifikant sedan 1930talet. Grundföreställningen hos de som presenterar runorna som verktyg i magisk praktik bygger på är att runorna inte enbart var ett alfabet utan också hade magiska och ockulta egenskaper. Varje runa tillskrivs kraft och betydelse vilket gör att runorna kan användas till spådom, magi och även som olika yogapositioner. Det har idag utvecklats former av runyoga som använder sig av futharken, eller ibland skriven som utharken, den yngre futharken, de anglo-saxiska runorna och det finns även de som fortfarande använder Armanen-runorna, men de grundläggande teknikerna är samma oberoende av vilken form av runalfabet som används (se exempelvis Welz 1998, Rice 2017 för armanen runorna, Eadig 2018 för anglo-saxiska runor, Karlsson 2002: 98-103 för uthark runor). 
Praktiskt sett går runyoga ut på att man ställer sig med kroppen på ett sätt som gör att kroppen formar den runa man vill kanalisera. Om man vill kanalisera den första runan i futharken, Fe-runan ställer man sig upp och lyfter fram båda armarna lätt uppåt med den ena höjd över den andra. Ibland inkluderas att man även vibrerar, med andra ord långsamt uttalar runans namn vid utandning så att det ska kännas i hela kroppen, de olika namnen på runorna så i fallet med Fe-runan vibrerar man samtidigt som man står i positionen, $\mathrm{Fe}, \mathrm{fe}, \mathrm{fe}, \mathrm{fe}$ osv. Under tiden man står där ska man även kontrollera sin andning och visualisera energier flöda genom kroppen. En modern utövare av runyoga skriver upplevelsen på följande sätt:

In accordance to many authors I can confirm that the runic postures are bioenergetic antennas which receive the various energies, symbolized by the runes. Tests with the pendulum during runic gymnastics showed an expansion and charging of the individual aura as well as an extensive radiation. The posture receives cthonic and celestial energies, thus activate and vitalize body and mind. This energy is also necessary to fullfill magical goals (Galdrtantz-Runedance 2013).

I förklaringarna till varför runyoga fungerar ser vi liknar de hos Kummer och Marby. Det handlar om energier från himmel och jord, och att man för in eller kanaliserar in runorna i kroppen. Dock så har det fokus på ras som ariosofin byggde på oftast försvunnit. I kontrast till vanlig yoga lyfts det magiska syftet med runyoga fram. En modern utövare av runyoga Eadig menar att genom att ställa sig i olika positioner kan man inte enbart nå andliga resultat utan även påverka ens liv mer direkt (Eadig 2018). Hur viktigt det är att kroppen liknar de olika runorna varierar. Thomas Karlsson, grundare av det magiska sällskapet Dragon Rouge, lyfter fram att en del av positionerna kan vara omständliga och att det har gjort att många har avfärdat hela praktiken (Karlsson 2002: 98). Karlsson menar inte heller att det finns några belägg för att det handlar om en äldre tradition men menar att det ändå finns värde i praktiken. Karlsson har utvecklat runyoga så det mer ska följa en form av dans för att undvika att det framstår som stelt och som charader. Att endast fokusera på att likna runorna menar Kalrsson leder till att man missar poängen med runorna: "The imitation of the runes often feel far-fetched. If we assume that the runes represent cosmic principles it is not importan to soley imitate their shape (Karlsson 2002: 98)." Hos Karlsson blir praktiken en del av det pereniallistiska magiska system som lärs ut inom Dragon Rouge och sättet man kanaliserar runorna binds ihop med färeställningar kring kundalini (Karlsson 2002: 99).

\section{RUNYOGA IDAG}

Idag utförs ofta runyoga som en del av större magiska eller hedniska andliga system, men populariteten av runyoga är svår att avgöra. Inom hedniska samfund som Samfundet Forn Sed Sverige förekommer det inte som en del av samfundets praktik och även 
om det kan förekomma att enskilda medlemmar utövar det verkar det inte vara vanligt enligt uppgifter från Birka Skogsberg som arbetar som gydja för Samfundet Forn Sed Sverige (privat korrespondens 2021-09-22). Det verkar snarare vara inom mer esoteriska sällskap som tagit in nordiska element som det är vanligare. Exempel på detta är Rune Gild som nämnts ovan och Dragon Rouge, vars grundare Thomas Karlsson har integrerat runyoga i sina texter om runmagi (Karlsson 2002: 98-103). Tekniker som starkt påminner om runyoga har också blivit en del av kampsportsystemet stav som beskrivs nedan. Det verkar dock finnas få som arbetar exklusivt med runyoga. Det finns få böcker som endast behandlar runyoga, oftast är det en del av en bredare runmagisk praktik. Vi ser detta hos Thorson och även hos Karlsson. Idag går det även att hitta instruktioner på Youtube och det finns ett antal kanaler som presenterar runyoga, även där oftast kombinerat med andra former av praktik som vanlig yoga eller andra former av nyandlighet (se exempelvis Rune Yoga \& The House of Mages som förutom rungyoga presenterar ett flertal klipp med konvetnionell yoga och Eadig som kombinerar presentationer om runyoga med inlägg om wicca). Eadig's Youtube-kanal presenterar en form av runyoga baserad på de anglo-saxiska runorna, men är primärt inriktad på häxkonst (Eadig 2021). Eadig tycks vara den största av de olika kanaler som presenterar runyoga med 34000 prenumeranter (Eadig 2021). Även om det därmed inte finns något som tyder på att runyoga har en popularitet som går att jämföra med vanlig yoga har praktiken hållits sig levande. Går man igenom de samtida texter och Youtube-presentationerna av runyoga verkar frågan om ras vara en icke-fråga. Snarare verkar det vara att det som lockar är det praktiska. Runyoga är enkel att utföra, den kräver inga rituella tillbehör och kan göras när som helst, det vanligt att de presenterar det som en form av gymnastik och därmed har träningskläder på sig när de utför de olika positionerna bland annat i på plattformar som Youtube. Runyoga kan tolkas som ett uttryck för problematiken kring att återskapa äldre religiösa traditioner som vi har relativt lite kunskap om och göra det på ett sådant att den kan kännas meningsfull för en modern människa. Vår kunskap om fornnordisk religion är bristfällig och det vi känner till ger mest insikter i kollektiva ritualer. Därmed finns ett behov av rituella tekniker som är anpassade för individen. Om vikingarna hade meditationstekniker eller fysiskt andliga övningar som påminner om den indiska yogan är osannolikt men för dagens hedningar kan ett sådant behov finnas. Runyoga kan fylla det behovet och de tyska runmagikerna skapade uppenbarligen ett system som hade inslag som fyllde behov av något som saknades och adapterades in i den mer esoteriska delen av den hedniska miljön i Nordamerika.

Få verkar tro att runyogan har djupa rötter i fornnordisk kultur. Det finns dock undantag. Den tyska runyoga-läraren Isabella Rose presenterar i sin video "What is Runic Yoga" en bild av det förkristna Norden där patriarkatet ännu inte har blivit dominerande och jämlikhet dominerar (Runen Yoga 2020). Rose menar att därmed får man kontakt med en äldre och mer jämlik dimension av tillvaron. Som inspiration har hon ha haft boken Folket bortom nordanvinden: från matriarkat till mansvälde av Göran och Gun- 
nel Liljeroth. Göran och Gunnel Liljeroths bok presenterade en teori om att innan asatron kom till Skandinavien existerade det ett gudinneorienterat matriarkat i Norden som tillbad gudinnan Hel. Spår av detta ansåg paret att man kunde hitta i folktro, och regioner i Sverige som Småland (Liljeroth och Liljeroth 1989; Liljeroth och Liljeroth 1997: 1316). Många som utövar runyoga verkar dock vara medvetna om att det är en modern konstruktion med ser positiva resultat av övningarna. Det är få som framhåller en äldre tradition, ett intressant undantag från detta är den ursprungligen norska traditionen stav.

\section{STAV: RUNYOGA SOM FAMILJETRADITION}

Ett av de mer intressanta sätten som runyoga har blivit en del av en samtida andlighet finner vi inom kampsporten stav. Ursprunget till stav är oklart, mycket beroende på att det fortfarande saknas någon större forskning kring ämnet. Enligt organisationen Stav International är stav en familjetradition som tidigare bara lärdes ut inom den norska familjen Hafskjold (Stav International). 1992 började Ivar Hafskjold lära ut stav för personer utanför familjen som en nordisk form av kampsport baserad på runorna (Stav International). Sanningen bakom stavs ursprung är omdiskuterad. Även om stav presenteras som en äldre tradition lyfter även Stav International upp att Hafskjold har tagit upp inslag från olika kampsporter från Asien (Ice and Fire Stav). En del av teknikerna inom stav påminner det starkt om Marby och Kummers runyoga, som att form kroppen efter runor. Dock hävdar Hafskjold och Stav International att stav inte är en ny tradition utan en familjetradition (Ice and Fire Stav). Där skiljer sig stav från andra former av runyoga som presenterats här. Även om Thorson menar att runyoga kan bygga på äldre traditioner är han mer vag om något har överlevt och hävdar inte att han är en del av en levande tradition vilket anhängare av stav gör (Thorson 1994: 17). På Stav Internationals hemsida skriver de att traditionen kan ha varit levande i minst 1500 år (Ice and Fire Stav). Ursprunget till begreppet stav beskrives på den svenska hemsidan: "Namnet stav kommer från uttrycket »sette stav», vilket var vad träningen och utförandet av runställningarna kallades när Ivar växte upp" (Stav International).

"Stav", en artikel från 2001 i Kvaser, tidskrift för det numrera nedlagda samfundet Nordiska Ringen, (senare Norröna Samfundet) presenterar artikelförfattaren, som endast går under förnamnet Roland, stav som ett system som sträcker sig till tiden innan vikingatiden och Hafskjold som en "uradelssläkt" (2001: 20). Retoriken med uråldriga anor och adelssläkter som bär med sig uråldriga hemligheter påminner om den retorik vi finner hos List och Liebenfels. Som nämnts påminner de run-positioner som lärs ut inom stav starkt om de som finns hos Marby. Några direkta belägg för Hafskjolds påståenden finns inte och ännu saknas akademiska studier om stav. Det verkar, baserat på närvaron av lokalgrupper som det går att får kontakt med genom Stav International existera grup- 
per i Skandinavien, liksom England och Tyskland (Stav International). Det saknas ännu forskning kring rörelsen så det är omöjligt att avgöra hur stor den är. ${ }^{2}$

Även om stav är en modern konstruktion som blandar nordiska referenser med japansk kampsport, yoga och ayurveda så har Hafskjold skapat ett system som för dess anhängare ger mer än bara en form av motion. Trots åldern på Rolands artikel ger den en övergripande bild av den världsbild som presenteras inom stav. I kontrast till andra former av runmagi använder man sig av den yngre futharken som endast har 16 runor. Roland menar att den yngre futharkens former bevisar att den har använts som riktmärke för olika yoga-positioner och inte bara som ett alfabet. Systemet är hierarkiskt och det finns fem typer av människor som både ses som grader och personlighetstyper: träl, karl, herse, jarl, könge. Detta menar artikeln avspeglar de sociala klasser som fanns i det fornnordiska samhället. Det finns också en binär bild av genus som relaterar till olika former av magi där galdr ses som maskulint och rationellt, medan sejd är feminint och intuitivt. Anhängare av stav uppmanas även att varje morgon och kväll gå igenom de 16 runställningarna, som bygger på den yngre futharken. I likhet med andra former av runyoga ska detta kombineras med andning, och leder till att "energiflödet i kroppen ökar” (Roland 2001: 21). Och vi ser här en fortsättning av samma mönster av att lyfta fram att runyoga genererar hälsa och skapar bra energiflöde i kroppen. I likhet med andra samtida former av runyoga saknas de rasbaserade föreställningarna.

\section{AVSLUTANDE REFLEKTIONER}

Runyoga uppstod i en miljö som var färgad av drömmar om den ariska rasen som gudomlig och som såg rasblandning som det främsta hotet mot tillvaron. Runyoga och rungymnastik var metoder varigenom som den germanska rasen skulle återvitalisera sig, och stärka både sina fysiska och psykiska förmågor. Men även om teknikerna legitimerades av rasistiska ideologier var systemet i sig inte fast $\mathrm{i}$ en rasistisk diskurs vilket utvecklingen av runyoga visar. Det gör att utvecklingen av runyoga kan ses som kontrasterande till Stephanie von Schnurbeins hypotes att $i$ intresset för, och ett utövande av andlighet baserad på fornnordisk mytologi inte går att separera från rasideologiska föreställningar (von Schnurbein 2016: 358) Runyogan utvecklades ur en rent rasideologisk miljö men som presenterats i artikeln har senare former bevarat de praktiska övningarna men ideologiskt snarare blivit en del av den bredare senmoderna nyandligheten som lägger fokus på individens, snarare än rasens, utveckling. Idag finns det ett flertal kanaler på bland annat Youtube som lär ut runyoga i olika former. Även om de rasistiska föreställningarna som Kummer och Marby byggde på saknas, återkommer föreställningar om elektromagnetiska fält, att kanalisera energi från himmel och jord och att runyoga handlar om magi

2. Under redigeringen av artikeln noterade jag 2021-10-16 att adressen för Stav International inte längre är funktionell. Detta kan tyda på att rörelsen inte längre är lika aktiv. 
på ett annat sätt än vanlig yoga. Detta verkar vara det tankegods som överlevt från ariosoferna. Trots ursprunget $\mathrm{i}$ en djupt rasistisk kontext är det tydligt att runyoga idag populariserats långt bort från dessa tankemönster. Att därmed anse att det skulle ligga en essentiell rasideologi bakom intresset för runyoga är svårt att argumentera för.

\section{LITTERATUR}

Baker, Alan. 2000. Invisible Eagle: The History of Nazi Occultism. London: Virgin.

Blavatsky, Helena. 1888. The Secret Doctrine: The synthesis of science religion and philosophy. London: The Theosophical Publishing Company.

Crowley, Aleister. 1972. Eight Lectures on Yoga. Dallas: Sangreal Foundation.

Eadig. 2018. Rune Yoga for Beginners. Tillgänglig online: https://www.youtube.com/watch?v=U-CErIjUOzI\&t=150s (besökt 2021-08-19).

Eadig. 2021. Eadig. Tillgänglig online: https://www.youtube.com/c/Eadig (besökt 2021-09-22).

Eddan: De Nordiska guda och hjältesångerna. 1992. Stockholm: Niloé.

Flowers, Stephen, och Guido von List. 1988. The Secret of the Runes by Guido von List. Rochester: Destiny Books.

Flowers, Stephen Edred. 2002. "The Idea of Integral Culture: A Model for a Revolt Against the Modern World". I Tyr: Myth-Culture-Tradition, utgiven av Colin Cleary Joshua Buckley och Michael Moynihan, 1:11-22. Atlanta: Ultra.

Galdrtantz-Runedance. 2013. Stàdhagaldr. Tillgänglig online: http://galdrtanz-runedance.blogspot.com/2013/03/stadhagaldr.html (besökt 2021-08-19).

Gardell, Mattias. 2003. Gods of the Blood: The Pagan Revival and White Separatism. Durham: Duke University Press. https://doi.org/https://doi.org/10.2307/j.ctv11vc85p.

Godwin, Joscelyn. 1996. Arktos: The Polar Myth in Science, Symbolism \& Nazi Survival. Kemptin: Adventures Unlimited Press.

Goodrick-Clarke, Nicholas. 1992. The Occult Roots of Nazism: Secret Aryan Cults and Their Influence on Nazi Ideology. London: I.B. Tauris \& Co.

Granholm, Kennet. 2013. "The Left-Hand Path and Post-Satanism: The Temple of Set and the Evolution of Satanism". I The Devils Party: Satanism in Modernity, utgiven av Per Faxneld och Jesper Aa Pedersen, 209-228. Oxford University Press. https://doi.org/10.1093/acprof:oso/9780199779239.003.0010. 
Hammer, Olav. 2003. Claiming Knowledge: Strategies of Epistemology from Theosophy to the New Age. Leiden: Brill.

Hau, Michael. 2003. The Cult of Health and Beauty in Germany: A Social History, 1890-1930. Chicago: The University of Chicago Press.

Ice and Fire Stav. Frequently Asked Questions About Stav. Tillgänglig online: https://www.iceandfire.org.uk/faqs.html (besökt 2021-12-20).

Karlsson, Thomas. 2002. Uthark: Nightside of the Runes. Sundbyberg: Ouroboros Produktion.

Kummer, Siegfried Adolf. 2017. Rune=Magic. Bastrop: Lodestar.

Lenthe, Eckehard. 2018. Wotans Awakening: The Life and Times of Guido von List 1848-1919. Dominion Press.

Liebenfels, Jörg Lanz von. 2002. Theozoologie: oder die Kunde von den Sodoms-Äfflingen und dem Götter-Elektron. Books on demand.

Liljeroth, Gunnel, och Göran Liljeroth. 1989. Folket bortom nordanvinden: från matriarkat till mansvälde. Lidköping: AMA-förlag.

Liljeroth, Gunnel, och Göran Liljeroth. 1997. Småländska antiqviteter: 300-årigt manuskript av Petter Rudebeck. Lidköping: AMA-förlag.

List, Guido. 1910. Die Bilderschrift der Ario=Germanen (Ario=Germanische Hieroglyphik). Wien: Guido von List Verlag.

List, Guido. 1912. Das Geheimnis der Runen (Gesammelte Werke). Wien: Guido von List Verlag.

List, Guido. 1913. Deutsch-mythologische Landschaftsbilder (Gesammelte Werke). Wien: Guido von List Verlag.

Mosse, George L. 1981. The Crisis of German Ideology: Intelectual Origins of the Third Reich. New York: Schocken Books.

O’Donoghue, Heather. 2007. "From Runic Inscriptions to Runic Gymnastics". I Old Norse Made New: Essays on the Post-Medieval Reception of Old Norse Literature and Culture, utgiven av David Clark och Carl Phelpstead. Exeter: Short Run Press Limited.

Pringle, Heather. 2006. The Master Plan. Himmler's Scholars and the Holocaust. London: Harper Perennial.

Rice, Marc. 2017. Rune Yoga (Armanen) - Dignity \& Success. Tillgänglig online: https://www.youtube.com/watch?v=mA37_tj1j6U (besökt 2021-09-26). 
Roland. 2001. "Stav". Tillgänglig online: http://stav.angerboda.se//artiklar/stav_kvaser.pdf (besökt 2021-08-19), Kvaser, nr. $6-7,20-23$.

Runen Yoga. 2020. What is Runic Yoga? Introduction of the Original. Tillgänglig online: https://www.youtube.com/watch?v=Fv6MHw4S9U8\&t=163s (besökt 2021-09-26).

von Schnurbein, Stefanie. 2016. Norse Revival: Transformations of Germanic Neopaganism. Leiden: Brill. https://doi.org/https://doi.org/10.1163/9789004309517.

Stav International. Om Stav. Tillgänglig online: http://www.stavinternational.org/se.html (besökt 2021-08-19).

Tacitus. 1980. Germania. London: Harvard University Press.

Thorson, Edred. 1984. Futhark: A Handbook of Rune Magic. York Beach: Weiser.

Thorson, Edred. 1994. . The Nine Doors of Midgard. A Complete Curriculum of Rune Magic. St. Paul: Llewllyn Publications.

Thorson, Edred. 2018. Rune Might: The Secret Practices of the German Rune Magicans. Rochester: Inner Traditions.

Treitel, Corina. 2004. A Science for the Soul: Occultism and the Genesis of the German Modern. Baltimore: John Hopkins University Press.

Weininger, Otto. 2015. Sex and Character. Scholar's Choice.

Welz, Karl Hans. 1998. Armanen Runes: The Rune Yoga Course. Tillgänglig online https://cdn.preterhuman.net/texts/religion.occult.new_age/Magick/Rune\% 20Yoga\%20Course.pdf (besökt 2021-09-27). 
